\title{
Erratum to: Perspectives on pre-fracture intervention strategies: the Geisinger Health System Osteoporosis Program
}

\section{E. D. Newman}

Published online: 23 August 2011

(C) International Osteoporosis Foundation and National Osteoporosis Foundation 2011

\section{Erratum to: Osteoporos Int}

DOI 10.1007/s00198-011-1695-x

This article contained an incomplete version of Fig. 2. The correct figure is reproduced here.

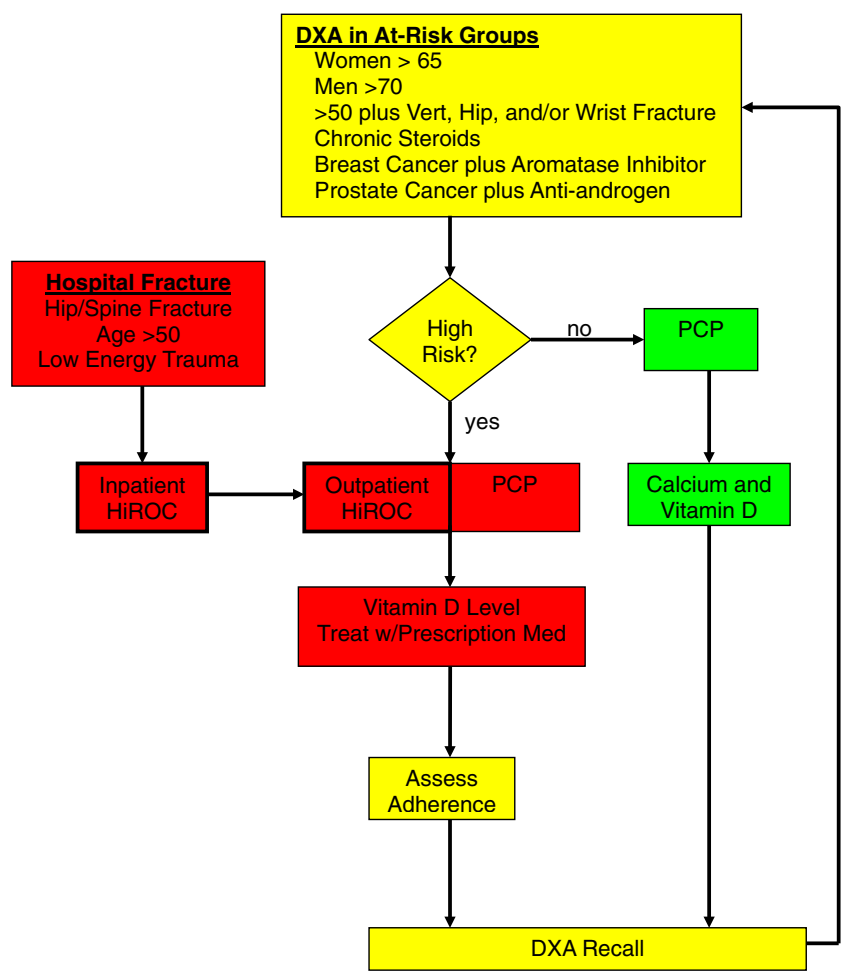

Fig. 2 System-wide osteoporosis care at Geisinger. At-risk groups are assessed proactively, and intervention programs seek out those at risk as well as those that have already sustained a fracture. A feedback loop ensures improved adherence and monitoring

The online version of the original article can be found at http://dx.doi. org/10.1007/s00198-011-1695-x.

E. D. Newman $(\square)$

Department of Rheumatology, Geisinger Health System,

100 N. Academy Avenue,

Danville, PA 17822-2152, USA

e-mail: enewman@geisinger.edu 